FRANCO MODIGLIANI

Massachusetts Institute of Technology

CHARLES STEINDEL

Massachusetts Institute of Technology

\title{
Is a Tax Rebate an Effective Tool for Stabilization Policy?
}

IN THE COURSE of the last decade, temporary changes in federal incometax liabilities have become a major tool of macroeconomic policy. The chief episodes so far have been the temporary surcharge of 1968-70 and the tax rebate of 1975 . Another rebate was proposed by the Carter administration in early 1977 but was subsequently withdrawn.

There has been a lively debate and wide disagreement in the economics profession about the efficacy of short-run changes in personal taxes as a device to stimulate aggregate demand and output. Transitory tax changes are advocated on the grounds that they can provide a prompt and temporary stimulus or restraint to the economy when it is needed and when permanent or longer-acting changes are not desirable because the structure of tax rates is deemed appropriate for the longer run. For a transitory tax change such as an income-tax rebate to accomplish its purpose, it should produce a large response in consumption per dollar of tax revenue lost by the government, and this response should be concentrated in a short time span following the tax reduction.

Economists working in the tradition of the permanent-income and life-

Note: The authors wish to thank the Research Division of the Federal Reserve Board, especially Jared Enzler; Allen Sinai of Data Resources, Inc.; and members of the Brookings panel for assistance with our work. Part of Charles Steindel's research has been supported by the Social Science Research Council. All errors are the authors' own. 
cycle theories of consumption, whose essence is that consumers endeavor to even out their consumption of goods and services over a long planning horizon, argue that temporary changes in the income tax are a poor instrument for stabilization because the consumption response will have the wrong shape. A temporary tax cut, it is argued, initially will be largely saved and will be spent only gradually. Similarly, a temporary tax increase will initially be largely absorbed by a corresponding large decline in personal saving, and only gradually reduce consumption, again over a long period of time. This view was advanced, for instance, by Robert Eisner, in relation to the 1968 surcharge. ${ }^{1}$

Opponents of this position contend that temporary changes in taxes will promptly and substantially affect consumer expenditures. One argument to support this belief could be that consumers are too myopic to distinguish between permanent and temporary changes in taxes. A more sophisticated argument might rest on the service-flow concept of consumption, as embodied in the permanent-income and life-cycle theories. In practice (as used, for example, in the consumption function of the MITPenn-Social Science Research Council-MPS-econometric model) consumption is defined as consumer expenditures on nondurable goods and services plus an estimate of the imputed flow of services from the existing stock of durable goods. Thus, even if temporary tax cuts are saved, in the sense that they do not significantly increase consumption on this definition, the saving might take the form of investment in consumer durable goods. Hence, a temporary tax cut might stimulate consumer spending, even if the permanent-income and life-cycle theories were valid with regard to consumption as they define it.

Still another argument is that while large transitory or windfall changes in income may be mainly absorbed by saving with little initial impact on consumption, as predicted by the permanent-income and life-cycle theories, small changes would be spent much like ordinary income. It is suggested that rebates of the magnitude of that enacted in 1975 and the one proposed in 1977 belong to the class of "small" changes.

Finally, others, prepared to accept the usefulness of the permanentincome life-cycle framework in general, would argue that a substantial fraction of such rebates will go to households whose consumption is con-

1. Robert Eisner, "Fiscal and Monetary Policy Reconsidered," American Economic Review, vol. 59 (December 1969), pp. 897-905, and Eisner, "What Went Wrong?" Journal of Political Economy, vol. 79 (May/June 1971), pp. 629-41. 
strained by credit rationing to be below optimum, and who will therefore rapidly spend them. ${ }^{2}$ These observers presumably would expect the rebate to evoke a substantial response, even if probably a smaller one than for a commensurate permanent tax reduction.

The debate about the effectiveness of temporary tax changes can be settled only by empirical evidence. It is, therefore, somewhat surprising that while there has been some empirical analysis of the 1968 income tax surcharge, ${ }^{3}$ there has been very little attempt to analyze the 1975 tax rebate episode. One attempt was recently carried out by Thomas Juster. ${ }^{4}$ He estimated a personal saving equation for the United States using a specification derived from the work of Houthakker and Taylor which relates personal saving to lagged saving and changes in disposable personal income. ${ }^{5}$ This specification is broadly consistent with the life-cycle model. Juster breaks disposable income into labor income, property income, transfer payments, taxes, and contributions for social insurance. His basic model predicts that the bulk of any change in taxes, whether permanent or temporary, is initially absorbed by opposite changes in saving, with consumption rising or falling only very gradually. Accordingly, Juster's conclusion that the 1975 rebate was treated by consumers much the same as any other tax change is consistent with the hypothesis that little of the rebate was spent initially. His results suggest that no more than 15 percent of the rebate was spent in the quarter it was paid.

A casual look at saving rates appears to show that temporary tax changes have only modest effects on consumption. After the imposition of the surcharge in the third quarter of 1968 , the saving rate declined sharply and continued at a low level until the second quarter of 1970, just

2. This view has been emphasized by, for example, James Tobin and Walter Dolde, "Wealth, Liquidity and Consumption," in Consumer Spending and Monetary Policy: The Linkages, Proceedings of a Monetary Conference (Federal Reserve Bank of Boston, 1971), pp. 99-146.

3. Arthur M. Okun, "The Personal Tax Surcharge and Consumer Demand, 196870," BPEA, 1:1971, pp. 167-204, and William L. Springer, "Did the 1968 Surcharge Really Work?" American Economic Review, vol. 65 (September 1975), pp. 644-59. An exchange on this topic between Okun and Springer is found in American Economic Review, vol. 67 (March 1977): Okun, "Did the 1968 Surcharge Really Work?: Comment," pp. 166-69, and Springer, "Did the 1968 Surcharge Really Work?: Reply," pp. 170-72.

4. Thomas Juster, "A Note on Prospective 1977 Tax Cuts and Consumer Spending" (University of Michigan, Institute for Social Research, 1977; processed).

5. H. S. Houthakker and Lester D. Taylor, Consumer Demand in the United States: Analyses and Projections (Harvard University Press, 1966; 2d ed., 1970). 
before the end of the surcharge. It jumped dramatically in the second quarter of 1975 when the rebate was paid out and then declined only to $71 / 2$ percent during the second half of the year, approximately the average level. However, since no serious attempt to explain consumption behavior predicts a constant saving rate, these casual observations are not conclusive. In what follows, we present an analysis of the 1975 rebate based on statistically estimated consumption equations. We first examine the consumption sector of three large econometric models-Data Resources, Inc. (DRI), Michigan, and MPS - to see what each implies about the effect of a rebate compared with a permanent (indefinite) tax change, and then examine the forecast error from these models during the rebate period. Finally, we examine the rebate using a single-equation model of consumer expenditures that we have constructed explicitly to test the effects of permanent versus transitory tax changes.

\section{Estimates from Large Models}

None of the three large econometric models that we use in our initial analysis of the rebate distinguish among changes in disposable income according to their source. By their structure, these models assume that the tax rebate will affect consumption to the same extent and with the same lags as any other change in income will. ${ }^{6} \mathrm{~A}$ test of the rebate's actual effectiveness thus consists of seeing how well these models track actual consumption over the period affected by the rebate.

While they all treat the rebate like any other kind of income, the models do differ substantially from one another in how they model the effects of income changes on consumption and thus in their predictions of the responses of consumption to the rebate. The DRI model predicts a very prompt response, with consumption directly affected by the rebate in the first two quarters after it is paid out. Both the Michigan and MPS models predict much more gradual responses. The DRI and Michigan models predict consumption at a considerable level of disaggregation, a fact that pro-

6. One consequence of this assumption is that, compared with a permanent tax reduction of, say, $\$ 10$ billion a year accomplished through lower withholding rates, a $\$ 10$ billion rebate in one quarter (which is a $\$ 40$ billion annual rate of increase in disposable income for that quarter) will be predicted to generate more consumption spending initially and for at least a few subsequent quarters. 
vides a more exacting test of their estimates of the rebate's effectiveness.

While the main aim of this paper is to analyze the response to the 1975 tax rebate, we should note that it was only one of three changes in tax and transfer programs implemented at about the same time. First, $\$ 8$ billion (a $\$ 32$ billion annual rate) was paid out during the second quarter under the rebate program. Second, tax withholding was reduced by $\$ 12$ billion at an annual rate starting in May 1975, in a change that was legislated as temporary but that many expected to be made permanent. The reduction was subsequently reenacted just before the end of the year, and we treat it as a permanent tax reduction in the analysis in this paper. Third, $\$ 1.7$ billion (a $\$ 7$ billion annual rate) was paid out in June to social security recipients. In addition to these specially legislated changes, starting in the third quarter social security payments jumped by $\$ 6$ billion at an annual rate as the result of automatic cost-of-living escalation. As we discuss more fully in connection with the consumption equations developed for this paper, we expect social security recipients to spend payments they receive promptly and fully. Thus we do not treat any of these payments to them as part of, or in parallel with, the tax rebate itself; we treat the tax rebate as the only change in disposable income during this period that might be expected to provoke a special response in consumer spending. However, in connection with the consumption equations developed in the latter part of this paper, we note how the analysis would be modified with a different treatment of these other changes.

\section{THE MPS MODEL}

We begin by examining the consumption sector of the MPS model as recently reestimated by Jared Enzler of the Research Division of the Board of Governors of the Federal Reserve System. ${ }^{7}$ The model has no single equation explaining total consumer expenditures. Rather, it has an equation explaining "consumption" ( $C O N)$ defined as purchases of nondurable goods and services plus the imputed rental value of the stock of durables, and another equation explaining consumer durable expenditure $(E C D)$. The effect of a tax cut on total consumer expenditures is then the sum of the effects on $C O N$ and on $E C D$, less the effect on the imputed rental value of durables which, however, cannot be significantly affected over a period of a few quarters.

7. Enzler kindly provided the simulations used in this analysis. 
The MPS equation for $C O N$ is in the spirit of the life-cycle hypothesis, which implies that consumption in period $t\left(C_{t}\right)$ is a linear function of the expected permanent value of nonproperty income net of tax in period $t$ $\left(Y L_{t}^{p}\right)$ and aggregate net worth at the start of period $t\left(W_{t-1}\right)$ :

$$
C_{t}=a Y L_{t}^{p}+b W_{t-1} .
$$

As in earlier versions of the MPS model, $Y L_{t}^{p}$ is replaced by a distributed lag on real disposable personal income per capita. ${ }^{8}$ The sum of the coefficients on disposable personal income is 0.694 , with the first coefficient 0.173 and subsequent coefficients gradually declining. The effect of a rebate in this equation would be modeled by raising disposable personal income by the amount of the rebate in one single quarter, and then tracing the effect of that one-quarter bulge in disposable income on consumption for that and subsequent quarters.

Expenditures on consumer durables are explained as a linear function of $C O N$ and of disposable personal income, plus a number of other variables reflecting the relative price of durables-the ratio of the price of durables to all consumption goods and the return on durables relative to financial assets. The coefficient of CON is 0.16 and that of disposable income 0.17 , both without any lag. Thus the effect of a rebate in the durables-demand equation is modeled by raising disposable income by the amount of the rebate and tracing the effect of that change in the quarter it occurs plus the effect of the change in CON over that and subsequent quarters.

The quantitative characteristics of this consumption sector can be illustrated by its predicted total expenditure response in the first year after a $\$ 10$ billion tax reduction. If the reduction takes the form of a one-time rebate, consumer spending is predicted to rise by $\$ 7$ billion during the first year. If it takes the form of reduced withholding, so that taxes are lower by $\$ 2.5$ billion each quarter, consumer spending is predicted to rise by $\$ 5.5$ billion during the first year.

How well the model accounts for the behavior of consumption after the major tax changes of 1964 and 1968 may give some indication of its usefulness with respect to the 1975 rebate. The MPS model understates the

8. The MPS definition of disposable personal income differs from the national income accounts version in that (a) it eliminates the interest paid by consumers, but adds back the imputed service income from durables; and (b) it treats federal personal income taxes on a liability rather than on an accrual basis. 
rise in consumer spending following the permanent tax cut of 1964, but only slightly. In the first three quarters of 1964 , it underestimates CON by a total of $\$ 4.3$ billion (1972 prices) at annual rates; but since it overestimates durable purchases by $\$ 2.6$ billion for the same period, it is nearly on the mark for total consumer expenditures. However, the model misses appreciably in the 1968 surcharge episode. From 1968:3 to 1970:2, it underestimates CON by a total of $\$ 39.4$ billion, or an average of $\$ 4.9$ billion a quarter; it underestimates $E C D$ by a total of $\$ 10$ billion, or an average of $\$ 1.25$ billion a quarter. Consumption is thus underestimated by an average of roughly $\$ 6.1$ billion a quarter over the surcharge period. It seems plausible to infer that at least some of this error arises because the model treats the surcharge like a permanent tax increase while consumers treated it as temporary and did not reduce consumption by as much as they would have in response to a permanent change.

\section{MODEL PERFORMANCE}

The performance of the MPS model following the 1975 rebate is analyzed in table 1. Because the two equations of the MPS are estimated with large autoregressive coefficients- 0.7 for $C O N$ and 0.65 for ECD-the table analyzes the prediction errors both with and without the autoregressive correction. The first five rows present results with the correction. Because (somewhat surprisingly) the MPS model had substantially overestimated consumption in 1975:1, the corrected forecast error, shown on row 1 , is considerably smaller in the quarter of the rebate than the uncorrected error in row 6 in the bottom part of the table. Even with the correction, the model overestimates consumption by $\$ 5$ billion in the first quarter, then has small overestimates the next two quarters, and finally starts underestimating consumption in 1976.

Row 2 gives the effect of the rebate predicted by the MPS. This is simply the difference between the actual forecast of the model and an alternative forecast computed on the assumption that there had been no rebatesubtracting from the second-quarter disposable income the amount of the rebate- $\$ 25.6$ billion (1972 prices) at annual rates. A comparison of rows 1 and 2 reveals that the model's overestimate for 1975:2 of $\$ 5$ billion is more than half of the effect that is supposed to result from the tax change. In other words, if the MPS model is used to predict consumption on the assumption that the rebate had zero effect, it would underestimate 
Table 1. Effects of the 1975 Tax Rebate According to the MPS Model, 1975:2-1976:3

Billions of 1972 dollars except as indicated

\begin{tabular}{|c|c|c|c|c|c|c|}
\hline \multirow[b]{3}{*}{ Type of equation and result } & \multicolumn{6}{|c|}{ Year and quarter } \\
\hline & \multicolumn{3}{|c|}{1975} & \multicolumn{3}{|c|}{1976} \\
\hline & 2 & 3 & 4 & 1 & 2 & 3 \\
\hline \multicolumn{7}{|l|}{ With autocorrelation correction } \\
\hline 1. Forecast error (actual - predicted) & -5.0 & -0.3 & -1.7 & 4.6 & 2.1 & 1.7 \\
\hline \multirow{2}{*}{\multicolumn{7}{|c|}{$\begin{array}{l}\text { 3. Estimated actual effect of rebate } \\
\text { (error assuming no rebate-row } 1+\end{array}$}} \\
\hline & & & & & & \\
\hline \multirow{3}{*}{$\begin{array}{l}\text { 4. Estimated actual effect cumulated, } \\
\text { as percent of rebate } \\
\text { 5. Predicted effect cumulated, as percen } \\
\text { of rebate }\end{array}$} & & & & & & \\
\hline & 16.0 & 29.7 & 34.4 & 60.9 & 74.6 & 84.8 \\
\hline & 35.5 & 50.4 & 61.7 & 70.3 & 75.8 & 79.3 \\
\hline \multicolumn{7}{|l|}{ Without autocorrelation correction } \\
\hline \multirow{3}{*}{$\begin{array}{l}\text { 6. Forecast error } \\
\text { 7. Estimated actual effect (row } 6+ \\
\text { row 2) } \\
\text { 8. Estimated actual effect cumulated, } \\
\text { as percent of rebate }\end{array}$} & -8.0 & -2.0 & -2.2 & 4.6 & 2.4 & 2.2 \\
\hline & 1.1 & 1.8 & 0.7 & 6.8 & 3.8 & 3.1 \\
\hline & 4.3 & 11.3 & 14.0 & 40.6 & 55.4 & 67.5 \\
\hline
\end{tabular}

Source: Derived from the equations for consumption and consumer durable expenditures of the MIT-Penn-Social Science Research Council econometric model, as explained in the text.

the amount in $1975: 2$ by $\$ 4.1$ billion $(-5+9.1)$. Clearly, this figure, reported in row 3 , provides an estimate of the "true" effect of the rebate on expenditure. It must, of course, be recognized that this figure represents but an unbiased point estimate of the rebate effect subject to any error that the model would have made in the relevant quarters had the rebate never been enacted. Finally, row 4 cumulates the estimated actual effects of row 3 and expresses them as percentages of the rebate.

As row 4 shows, only an estimated 16 percent of the rebate was spent in the quarter in which it was paid out, and 34 percent was spent by the end of 1975. By 1976:1, four quarters after the enactment of the rebate, its effect is predicted to become quite modest, as shown in row 2. However, in this and the following two quarters, the MPS appreciably underestimates consumers' expenditure even allowing for the tax rebate. This shortfall implies a sharp rise in the estimated actual effects of the rebate in the 1976 quarters; but this may reflect, at least in part, other factors 
biasing the model's forecast downward. Indeed, as row 4 shows, in quarters four to six after the rebate, the additional expenditure generated is estimated at 50 percent of the rebate, compared with only 34 percent generated in the first three quarters.

The calculations in rows 6,7 , and 8 repeat the results of this analysis with no correction for error autocorrelation. They show an even smaller estimated effect of the rebate in the initial quarter and a somewhat larger rise starting in 1976.

According to the MPS, the rebate clearly stimulated consumer expenditure. But the estimated effect is relatively modest, at least in the first three quarters: no more than one-third of the rebate appears to have been spent in this period. This effect is substantially lower than that predicted by the model had consumers responded to the rebate as to an ordinary tax change. This is shown by the model's overprediction of consumption, which is large in 1975:2 and persists at more modest rates throughout the rest of 1975. It is also brought out in comparisons of the estimated cumulated response (row 4) with the cumulated response predicted by the model (row 5). It is apparent that through 1975 the response is consistently about half as large as the predicted one, a result reminiscent of the 1968-69 experiment. The alternative estimate of the cumulated effect given in line 8 makes the difference even more dramatic. The model further suggests that a substantial response to the rebate occurred in 1976-especially in the first quarter-but this estimate may not be very reliable.

\section{THE DRI MODEL}

The DRI consumption sector splits consumer expenditures into many categories. For most categories, expenditure is estimated as a function of the current and previous quarter's disposable income, with 60 percent of the weight on the current quarter, plus a variety of other variables relating in particular to consumer debt. Thus in this model, the full effect of a rebate is predicted to occur within the first two quarters.

Table 2 gives the effect of the 1975 rebate on total consumption and in several major subcategories of consumption for 1975:2 and 1975:3, the only quarters directly affected in the DRI model. The model predicted total consumption quite accurately, overestimating only slightly in the second quarter and being essentially on target in the third quarter of 1975 . This implies that the rebate was promptly spent, just like any other in- 
Table 2. Effect on Consumption Expenditures of the 1975 Tax Rebate, by Selected Categories, DRI Model, 1975:2 and 1975:3

Billions of 1972 dollars except as indicated

\begin{tabular}{|c|c|c|c|c|}
\hline \multirow[b]{2}{*}{$\begin{array}{l}\text { Year and } \\
\text { quarter, and } \\
\text { consumption } \\
\text { category }\end{array}$} & \multirow[b]{2}{*}{$\begin{array}{c}\begin{array}{c}\text { Forecast } \\
\text { error } \\
\text { (actual - } \\
\text { predicted) } \\
(1)\end{array} \\
\end{array}$} & \multirow[b]{2}{*}{$\begin{array}{c}\text { Predicted } \\
\text { effect of } \\
\text { rebate } \\
(2)\end{array}$} & \multicolumn{2}{|c|}{ Estimated actual effect } \\
\hline & & & $\begin{array}{c}\text { Error assuming } \\
\text { no rebate } \\
\text { (3) }\end{array}$ & $\begin{array}{l}\text { Cumulated } \\
\text { as percent } \\
\text { of rebate } \\
\text { (4) }\end{array}$ \\
\hline \multicolumn{5}{|l|}{$1975: 2$} \\
\hline Durables & -1.5 & 3.4 & 1.9 & 7.3 \\
\hline Clothing & 0.1 & 1.2 & 1.3 & 5.0 \\
\hline Food & 1.3 & 1.6 & 2.9 & 11.2 \\
\hline Other nondurables & -0.1 & 0.9 & 0.8 & 3.1 \\
\hline Housing & -0.5 & 1.1 & 0.6 & 2.3 \\
\hline $\begin{array}{l}\text { Total consumer } \\
\text { spending } \mathrm{b}\end{array}$ & -0.9 & 9.6 & 8.7 & 33.0 \\
\hline \multicolumn{5}{|l|}{$1975: 3$} \\
\hline Durables & 0.0 & 2.3 & 2.3 & 16.2 \\
\hline Clothing & -0.1 & 0.8 & 0.7 & 7.7 \\
\hline Food & 1.6 & 1.0 & 2.6 & 21.2 \\
\hline Other nondurables & 0.8 & 0.6 & 1.4 & 8.5 \\
\hline Housing & 0.7 & 0.7 & 1.4 & 7.7 \\
\hline $\begin{array}{l}\text { Total consumer } \\
\text { spending }\end{array}$ & -0.1 & 6.4 & 6.3 & 58.0 \\
\hline
\end{tabular}

Source: Derived from the consumption sector of the Data Resources, Inc., econometric model, as explained in the text.

a. Column 1 plus column 2.

b. Total includes components of consumer spending not listed separately here.

crease in disposable income. Specifically, column 4 shows that an estimated 58 percent of the rebate was spent in the first two quarters, as compared with 62 percent predicted by the model (the effects of column 2 for the two quarters expressed as a percent of the rebate).

Taking account of changes in consumption rather than levels alters the picture somewhat. The model underestimated consumption by some $\$ 3$ billion in the first quarter of 1975 , so that the forecast change overestimated the actual rise in consumption from the first to the second quarter by almost $\$ 4$ billion. If the rebate is removed from disposable personal income (the column 3 concept), the second-quarter increase is underestimated by $\$ 5.7$ billion. Finally, because DRI again underestimates consumption by $\$ 4 \frac{1}{2}$ billion in the fourth quarter, it underestimates the change in consumption by about this same amount. If the rebate is removed from disposable income, this error becomes an overestimate of only about $\$ 2$ billion. 
Thus, in terms of level forecasts, the DRI model strongly supports the view that the rebate was largely spent within the first two quarters, as though the public had treated it much as a permanent rise and fall in taxes. On the other hand, in terms of changes in consumption, the observed values fall roughly midway between those predicted by the model assuming zero and full effect of the rebate. Considering that the model was estimated through 1975:4, it may be that the close fit of the two rebate quarters was achieved at the expense of underestimating the neighboring quarters. ${ }^{9}$

Further doubts are raised by an examination of the categories of commodities on which, according to DRI, the rebate was spent. Column 3 implies that a good share of the rebate was spent on durable goods and clothing. Over the two quarters, these account for 41 percent of the total estimated expenditure of $\$ 15$ billion, and for 24 percent of the rebate. These implications seem eminently plausible: durables and clothes are precisely the goods in which a proponent of the life-cycle and permanentincome hypotheses would expect some of a windfall to be "invested," since they provide a flow of services for some time-they are not "consumed" at once. But the DRI model also implies that 21 percent of the rebate was spent on food, or nearly as much as on durables and clothing combined. Another 16 percent is supposed to have been spent on housing services (mainly rents, both actual and imputed) and on other nondurables (such items as drugs, tobacco, and books). While we are open to the suggestion that some of the rebate was used to finance a night on the town, we find it hard to believe that 60 percent of the expenditure generated by it went for food, a larger apartment, or other nondurables. At the same time, one must remember that the estimated rebate effects are point estimates, which are subject to sizable error.

\section{THE MICHIGAN MODEL}

The Michigan model is similar to the DRI in that it splits consumer spending into several categories-automobiles, furniture, other durables, nondurables, and services-and it is similar to the MPS in that it uses long distributed lags on disposable personal income, and thus predicts effects from the rebate lasting for several quarters. Table 3 gives the rebate effects on total consumption and several subcategories estimated by the Michigan

9. The MPS model, in which the effect of the rebate is much more spread out in time, overestimates 1975:1 appreciably, and 1975:4 moderately. 
Table 3. Effect on Consumption Expenditures of the 1975 Tax Rebate, by Selected Categories, Michigan Model, Quarterly, 1975:2-1976:3

Billions of 1972 dollars except as indicated

\begin{tabular}{|c|c|c|c|c|}
\hline \multirow[b]{2}{*}{$\begin{array}{l}\text { Year and } \\
\text { quarter, and } \\
\text { consumption } \\
\text { category }\end{array}$} & \multirow[b]{2}{*}{$\begin{array}{c}\text { Forecast } \\
\text { error } \\
\text { (actual- } \\
\text { predicted) } \\
\quad(I)\end{array}$} & \multirow[b]{2}{*}{$\begin{array}{l}\text { Predicted } \\
\text { effect of } \\
\text { rebate } \\
(2)\end{array}$} & \multicolumn{2}{|c|}{ Estimated actual effect } \\
\hline & & & $\begin{array}{l}\text { Error assuming } \\
\text { no rebate } \\
\text { (3) }\end{array}$ & $\begin{array}{c}\text { Cumulated } \\
\text { as percent } \\
\text { of rebate } \\
\text { (4) }\end{array}$ \\
\hline \multicolumn{5}{|l|}{$1975: 2$} \\
\hline \multicolumn{5}{|l|}{ Durables other } \\
\hline $\begin{array}{c}\text { Nondurables and } \\
\text { services }\end{array}$ & -6.4 & 5.1 & -1.3 & -5.1 \\
\hline Subtotal & -5.3 & $\begin{array}{l}3.1 \\
5.5\end{array}$ & 0.2 & $\begin{array}{r}-5.1 \\
0.8\end{array}$ \\
\hline Furniture & 2.1 & 2.6 & 4.7 & 18.4 \\
\hline $\begin{array}{l}\text { Total consumer } \\
\text { spending }\end{array}$ & -3.2 & 8.1 & 4.9 & 19.2 \\
\hline \multicolumn{5}{|l|}{$1975: 3$} \\
\hline $\begin{array}{l}\text { Durables other } \\
\text { than furniture } \\
\text { Nondurables }\end{array}$ & -1.1 & 4.0 & 2.9 & 17.2 \\
\hline and services & -1.0 & 2.5 & 1.5 & 0.8 \\
\hline Subtotal & -2.1 & 6.5 & 4.4 & 18.0 \\
\hline Furniture & 4.7 & -1.3 & 3.4 & 31.6 \\
\hline $\begin{array}{l}\text { Total consumer } \\
\text { spending }\end{array}$ & 2.6 & 5.2 & 7.8 & 49.6 \\
\hline $1975: 4$ & & & & \\
\hline $\begin{array}{l}\text { Durables other } \\
\text { than furniture } \\
\text { Nondurables }\end{array}$ & -1.4 & 0.6 & -0.8 & 14.1 \\
\hline and services & -1.3 & 1.5 & 0.2 & 1.6 \\
\hline Subtotal & -2.7 & 2.1 & -0.6 & 15.7 \\
\hline Furniture & 7.3 & 0.6 & 7.9 & 62.5 \\
\hline $\begin{array}{l}\text { Total consumer } \\
\text { spending }\end{array}$ & 4.6 & 2.7 & 7.3 & 78.2 \\
\hline
\end{tabular}

model. Since every equation in the model contains the lagged dependent variable, the predicted values come from dynamic simulations that use the computed lagged dependent variable rather than the actual value. The model underestimated consumption by a large $\$ 9.4$ billion in 1975:1. It then overestimated by some $\$ 3$ billion in the rebate quarter, 1975:2, and underestimated by growing amounts in subsequent quarters, with the error peaking at a remarkable $\$ 12$ billion in 1976:1. As noted in discussing the 
Table 3. (Continued)

\begin{tabular}{|c|c|c|c|c|}
\hline \multirow[b]{2}{*}{$\begin{array}{c}\text { Year and } \\
\text { quarter, and } \\
\text { consumption } \\
\text { category }\end{array}$} & \multirow[b]{2}{*}{$\begin{array}{l}\text { Forecast } \\
\quad \text { error } \\
\text { (actual - } \\
\text { predicted) } \\
\quad(I)\end{array}$} & \multirow[b]{2}{*}{$\begin{array}{l}\text { Predicted } \\
\text { effect of } \\
\text { rebate } \\
(2)\end{array}$} & \multicolumn{2}{|c|}{ Estimated actual effect } \\
\hline & & & $\begin{array}{l}\text { Error assuming } \\
\text { no rebate } \\
\text { (3) }\end{array}$ & $\begin{array}{c}\text { Cumulated } \\
\text { as percent } \\
\text { of rebate } \\
\text { (4) }\end{array}$ \\
\hline \multicolumn{5}{|l|}{ 1976:1 } \\
\hline $\begin{array}{l}\text { Durables other } \\
\text { than furniture }\end{array}$ & 2.2 & 0.7 & 2.9 & 25.4 \\
\hline $\begin{array}{c}\text { Nondurables and } \\
\text { services }\end{array}$ & 1.7 & 0.9 & 2.6 & 11.7 \\
\hline Subtotal & 3.9 & 1.6 & 5.5 & 37.1 \\
\hline Furniture & 8.0 & -0.3 & 7.7 & 92.6 \\
\hline $\begin{array}{l}\text { Total consumer } \\
\text { spending }\end{array}$ & 11.9 & 1.3 & 13.2 & 129.7 \\
\hline \multicolumn{5}{|l|}{$1976: 2$} \\
\hline $\begin{array}{l}\text { Durables other } \\
\text { than furniture }\end{array}$ & -1.3 & -0.1 & -1.4 & 19.9 \\
\hline $\begin{array}{c}\text { Nondurables and } \\
\text { services }\end{array}$ & 1.1 & 0.6 & 1.7 & 18.4 \\
\hline Subtotal & -0.2 & 0.5 & 0.3 & 38.3 \\
\hline Furniture & 8.4 & 0.2 & 8.6 & 126.2 \\
\hline $\begin{array}{l}\text { Total consumer } \\
\text { spending }\end{array}$ & 8.2 & 0.7 & 8.9 & 164.5 \\
\hline $1976: 3$ & & & & \\
\hline $\begin{array}{l}\text { Durables other } \\
\text { than furniture }\end{array}$ & -2.5 & -0.2 & -2.7 & 9.4 \\
\hline Nondurables and & & & & \\
\hline services & 3.0 & 0.5 & 3.5 & 32.0 \\
\hline Subtotal & 0.5 & 0.3 & 0.8 & 41.4 \\
\hline Furniture & 8.9 & 0.1 & 9.0 & 161.3 \\
\hline $\begin{array}{l}\text { Total consumer } \\
\text { spending }\end{array}$ & 9.4 & 0.4 & 9.8 & 202.7 \\
\hline
\end{tabular}

Source: Derived from the consumption sector of the Michigan econometric model, described in the text.

a. Column 1 plus column 2.

DRI model, any model that underestimated consumption greatly before and after the rebate will assert that a large fraction of the rebate was spent. As column 4 shows, the Michigan model implies that half the rebate was spent in two quarters, and more than 100 percent in one year.

The model's specifications imply that between a fifth and a quarter of the rebate would be spent on durables other than furniture in the first four quarters after the rebate (column 2), and this appears to be what actually 
was spent on these goods, according to the model's projections (column 4). (The reader is again reminded that relatively large standard errors undoubtedly go with the estimated rebate effects that we can calculate.) The model further asserts that a large fraction of the rebate should be spent on nondurable goods and services, but only 12 percent of the rebate was actually spent in these categories by the end of the first year (column 4). In these categories, the estimated actual effects of the rebate from the Michigan model are not out of line with what the permanent-income lifecycle hypothesis would predict. However, the aggregate consumption prediction of the Michigan model also rests on an implausibly large estimate of the amount of the rebate spent on furniture-almost two-thirds in three quarters, and over 150 percent in six quarters! This estimate comes, of course, from the large underestimation of furniture expenditure in 1975 and 1976, and suggests that the furniture equation is quite unstable. If the true effect of the rebate on furniture was no more than the model would predict (column 2), then less than a quarter of the rebate went into total consumption spending in the first two quarters, and about 40 percent in a year, which is even lower than the estimates from the MPS and from our own model (see below). ${ }^{10}$

\section{An Alternative Approach to the Treatment of Tax Changes}

We have constructed a model of consumer expenditures designed to test explicitly for differences in the effects of permanent and transitory changes in tax liabilities. Our framework is the life-cycle hypothesis of saving in its more general form. ${ }^{11}$ This framework supposes that consumers respond to changes in labor income and wealth in a somewhat more complicated fashion than equation 1 above suggests. The basic hypothesis behind the extension is that changes in the rate of return play a role in determining the rate at which consumers spend out of current human and nonhuman resources. Simply put, the coefficients of both in-

10. Measuring the rebate effect by a nondynamic simulation does not qualitatively change the results. A very large fraction (about one-third) of the rebate is estimated to have been spent on furniture by the end of 1975 , while only a relatively moderate amount (about another third) is spent on all other components of consumer spending.

11. Franco Modigliani, "The Life Cycle Hypothesis of Saving Twenty Years Later," in Michael Parkin and A. R. Nobay, eds., Contemporary Issues in Economics (Manchester University Press, 1975). 
come and wealth of the standard life-cycle model are functions of the rate of return, which leads to

$$
C_{t}=\left(a_{0}+a_{1} r_{t}\right) Y L_{t}^{p}+\left(b_{0}+b_{1} r_{t}\right) W_{t-1},
$$

where $r_{t}$ is the long-run rate of return net of taxes. The term $r_{t} W_{t-1}$ can be interpreted as permanent property income $\left(Y P_{t}^{p}\right)$; and the term in $r_{t} Y L_{t}^{p}$ can be dropped on the grounds that it is supposed to be small, which helps to reduce multicollinearity problems. Thus equation 2 reduces to

$$
C_{t}=a_{0} Y L_{t}^{p}+b_{1} Y P_{t}^{p}+b_{0} W_{t-1} .
$$

The sign of $b_{1}$ depends on the relative strength of the substitution and income effects; it is positive if, as we think more likely, the income effect of a higher rate of return, which reduces saving by making it easier for a consumer to attain a given saving goal, outweighs the substitution effect, which makes a larger savings goal easier to reach and thus more tempting. We therefore hypothesize that $b_{1}$ should be positive but less than one (which may be taken as an upper bound as substitution approaches zero).

In order to measure permanent labor and property income, we needed to estimate the taxes on each. In line with the life-cycle hypothesis and the procedure in the MPS model we treated taxes on a liability rather than on a cash basis and allocated total tax liability between the two components following the procedure of Ando and Brown. ${ }^{12}$ The effective tax rates were calculated as taxes on labor and property income divided by gross labor and property income. ${ }^{13}$ Finally, since our tax rates are based on annual data, to avoid overly abrupt changes at the end of the year we smoothed the quarterly series by calculating the applicable tax rate in a quarter as the mean of the effective tax rate for the current and past quarters.

We tested two ways of estimating permanent after-tax labor and property income. The first is the traditional one of using current income after tax and a polynomial distributed lag on past income after tax. The lag

12. Albert Ando and E. Cary Brown, "Lags in Fiscal Policy," in Stabilization Policies, Prepared for the Commission on Money and Credit (Prentice-Hall, 1963), pp. 97-163. Details on the allocation of taxes, both the division and the quarterly allocation, can be obtained from the authors. Other taxes and nontaxes were added to consumption.

13. Personal contributions for social insurance were considered a tax on labor income. We see no merit in the hypothesis that these contributions are perceived by households as a form of saving, and some tests confirmed that they could be properly lumped with income taxes. 
extends over six quarters for labor income and eight quarters for the more noisy property income. This traditional approach implicitly assumes that consumers form expectations about future tax liabilities by using the same distributed lag of past tax liabilities that they use to estimate permanent gross income from past gross income. It implies that they respond to a change in income resulting from a permanent tax change in the same way that they respond to variations in before-tax income, which presumably are partly transient. It is clearly a very questionable assumption.

The alternative approach estimates permanent gross income using a distributed lag on past gross income and subtracting from it an estimate of permanent taxes obtained by applying the latest effective tax rate. This procedure implies that permanent tax changes, unlike changes in gross income, produce their full effects immediately (except for the two-quarter smoothing mentioned above).

This alternative approach would clearly be inappropriate whenever a tax change is regarded as transitory by a significant portion of consumers. For the 1968 temporary surcharge we deal with this problem by estimating the equation as though the tax increase had been an ordinary permanent one, but adding a dummy variable for the eight quarters of its duration. The size and significance of this dummy should provide some evidence on the extent to which consumers regarded the surcharge as transitory. We estimate our equation only through 1975:1 in order to prevent the rebate of 1975 from contaminating the coefficients.

Labor income is defined as salaries and wages plus other labor income plus an estimate of the imputed labor income accruing to proprietors. Property income is defined as dividends, rents, and interest, plus the nonlabor residual of proprietors' income.

The two remaining components of personal income, social security and other transfer payments, are entered separately on the grounds that they tend to be concentrated among groups whose income is lower than their lifetime norm. Hence, in the spirit of the life-cycle hypothesis, we expect that the propensities to consume out of these payments-certainly the early impact-would be appreciably higher than that out of labor income. For social security benefits we expect a very high propensity to consume, possibly in excess of unity. The people receiving these benefits are already retired and should have propensities to consume close to one; moreover, an increase in these benefits should tend to reduce saving or increase con- 
sumption of those still working by increasing the expected size of retirement income.

Other investigators, such as Lester Taylor and Thomas Juster, have found very high coefficients for the sum of these two components of transfer payments in equations explaining changes in saving. ${ }^{14}$ In contrast to the life-cycle implications just described, these results imply an improbably low marginal propensity to consume rather than an exceptionally high one. We suggest that these results are largely artifacts of data definition and measurement. Before the social security system was indexed in 1972, the federal government on at least three occasions-during the third quarter of 1965 and the second quarters of 1970 and 1971-increased benefit levels and made the increases retroactive to the first of the year. Thus, in these quarters massive increases in old-age, survivors, disability, and health insurance benefits are recorded in the national accounts. ${ }^{15}$ It is reasonable to suppose that the bulk of these windfall benefits were saved in the quarter they were paid, and these quarters also show sharp increases in the saving rate. (This seems to explain, for instance, the increase in the saving rate in 1970:2, the quarter before the end of the surcharge.) Because the first difference in social security payments is reasonably smooth except for these "bumps," it is understandable how one might obtain a low coefficient for this variable in an equation explaining the first difference of saving.

To deal with this problem, we have constructed a variable approximating the windfall social security benefits. We define the windfall as the increase in OASDHI benefits in the windfall quarter, and remove this variable from the OASDHI benefit variable, adding it as a separate "semidummy" variable.

The rest of the transfer payments were treated as a separate variable. No distributed lags were used on either transfers or OASDHI benefits since they did not seem to be called for by the model, and in fact when tested were found to be insignificant and small.

Our estimated equations also contain a variable to capture the income expectations of the unemployed, which may be important in periods of

14. Lester D. Taylor, "Saving out of Different Types of Income," BPEA, 2:1971, pp. 383-407, and Juster, "A Note on Prospective 1977 Tax Cuts and Consumer Spending."

15. See relevant issues of Survey of Current Business for the details. 
severe unemployment like that beginning in 1974. The variable, employed earlier by Modigliani and Ando, is based on the conjecture that the income expectation of the average unemployed worker is proportional to the average income of the employed. ${ }^{16}$ It is formed as the current and lagged values of the product of the number of unemployed times labor income divided by the number of employed. The same treatment of taxes that was used for the expected labor income of the employed was repeated for that of the unemployed.

In order to achieve more efficient estimates, the (iterated) CochraneOrcutt technique was used to estimate the coefficient of serial correlation and the equations were then transformed by the estimates. Finally, in order to reduce heteroskedasticity, for purposes of estimation all variables were scaled by current labor income after taxes.

Table 4 reports the estimated equations for $C O N$ and for consumer expenditure, which is our main concern here. ${ }^{17}$ All variables are in per capita 1972 dollars. The estimation period for all equations is from 1955:4 to $1975: 1$.

Equation 4.1 uses the conventional treatment of taxes, while 4.2 uses our "permanent tax" approach, both with consumption as the dependent variable. Our alternate approach, 4.2 , produces a somewhat better fit-a modestly smaller standard error as well as a somewhat smaller autoregression coefficient for the error, implying a smaller variance for the raw error $u$. In addition, it yields generally more sensible coefficient estimates. The coefficient of wealth $(W)$, which is distinctly low in 4.1 as compared with the results of many other studies, is nearly 50 percent higher in 4.2 . Similarly, the estimates of the coefficients of transfer $(T R)$ and of social security benefits $(S S)$, which we expected to be close to unity, are higher in 4.2, and much higher than some of the estimates of others mentioned earlier, though they still remain lower than our prior expectations. The longrun marginal propensity to consume out of labor income $-L Y$ and $L Y G$ $\left(1-T_{L}\right)$-is about 0.75 in each equation, with the short-run (impact) propensity about half of the long-run one. The sum of the coefficients on property income $-P Y$ and $P Y G\left(1-T_{P}\right)$-is positive, which is consistent

16. Albert Ando and Franco Modigliani, "The 'Life Cycle' Hypothesis of Saving: Aggregate Implications and Tests," American Economic Review, vol. 53 (March 1963), pp. 55-84.

17. In the $C O N$ equations, the imputed rental income of durables was added to property income and interest paid by consumers was subtracted from it. 
with our expectation that the income effect dominates the substitution effect. The shape of the distributed lag is again more reasonable in 4.2, with a smaller proportion of the total weight attached to the current value. However, the sum of the coefficients in both equations is somewhat larger than one, which is not consistent with our expectations, and which one of the authors is investigating further. We note, however, that Modigliani and Tarantelli found similar results for a consumption function estimated for Italy..$^{18}$

The social security dummy is negative in each equation (though insignificant). This unexpected result is, however, consistent with the hypothesis that these windfall increases in OASDHI benefits had little immediate positive effect on consumer spending. Finally, the coefficient for the current value of the expected income of the unemployed $(U \cdot L Y)$ is quite low in each equation. It appears that wealth (which should reflect cyclical components) and transfers (which include unemployment insurance benefits) pick up much of the effect of the current value. In each equation, the lagged effect is fairly high and marginally significant.

The equations for consumer expenditure, 4.3 and 4.4, differ from those for $C O N$ primarily in that the distribution of the coefficients on the income variables, both labor and property, is shifted heavily toward the present, with the coefficient of the current variable generally accounting for some two-thirds of the total weight. Qualitatively, this phenomenon is to be expected in view of the large evidence that investment in durable goods is rather responsive to transitory income and saving. However, the extent of the shift is somewhat surprising and has the undesirable consequence of appreciably reducing the differential effect of the two alternative ways of treating taxes because the current value of after-tax income is identical in the two alternatives. As a result, the differences in fit and in individual coefficients between 4.3 and 4.4 are much smaller than the differences between 4.1 and 4.2 , and frequently they are quite minor. The coefficients of wealth are close to 0.04 , which is more nearly consistent with earlier studies (especially since we include property income as a separate variable). The coefficients of transfers are quite close to one and those of social security are also slightly higher than in the CON equations. Finally, the

18. F. Modigliani and E. Tarantelli, "The Consumption Function in a Developing Economy and the Italian Experience," American Economic Review, vol. 65 (December 1975), pp. 825-42. 
Table 4. Estimated Consumption Functions, Alternative Treatment of Taxes, 1955:4-1975: ${ }^{a}$

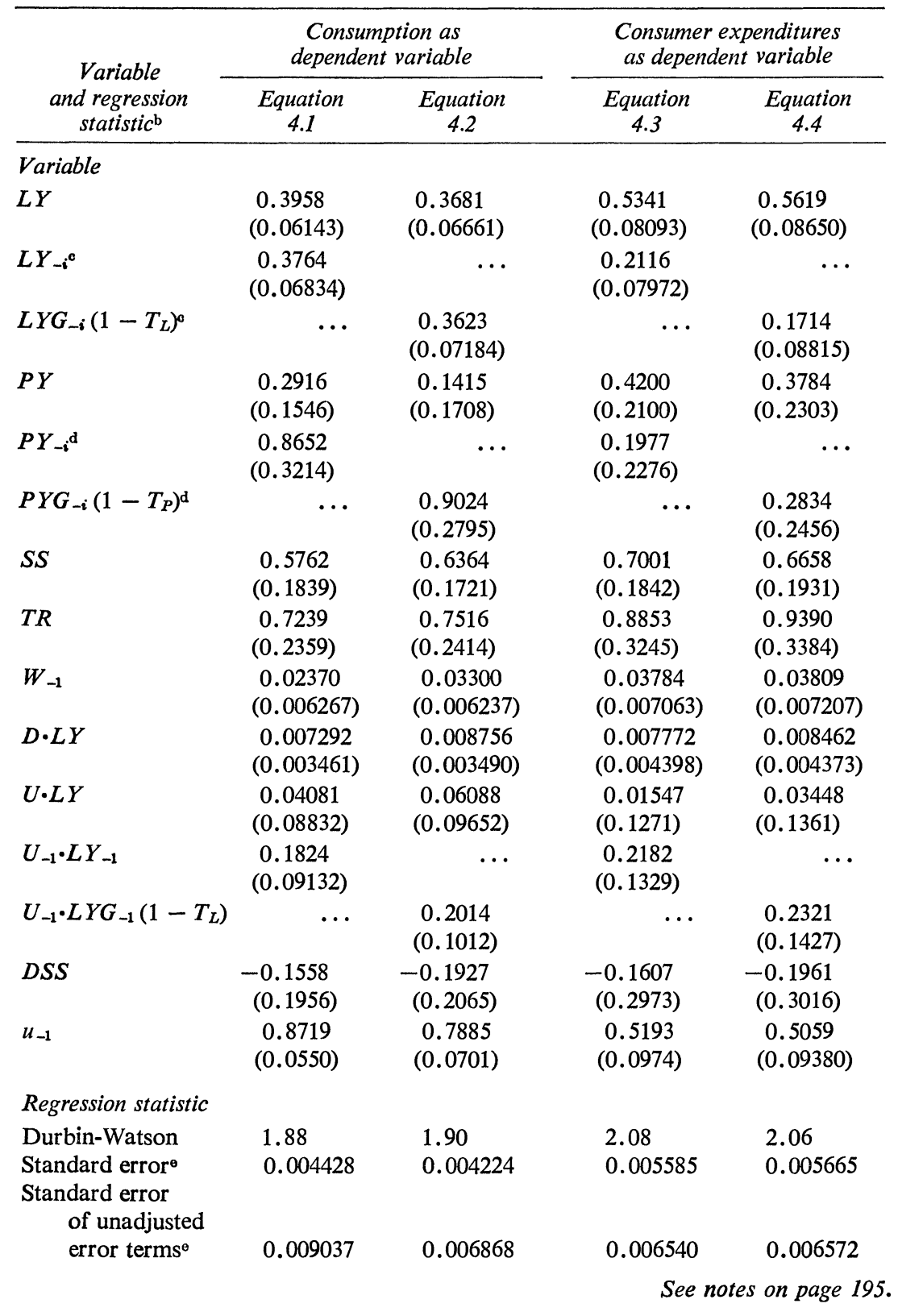


sum of the coefficients of property income is now around two-thirds, though unfortunately the estimates are subject to large error, presumably reflecting a good deal of multicollinearity.

\section{TAX CHANGES OF 1964 AND 1968}

We next apply our equations to consumer expenditures to study the major tax-change episodes that preceded the 1975 rebate. The tax cut of 1964 was of indefinite duration and presumably most people understood that it was. If our hypothesis that permanent tax cuts at once affect permanent net income and hence consumption is a good approximation, then our permanent tax equation, 4.2 , should correctly estimate consumption in the early quarters of 1964 , while the conventional equation, 4.1, should underestimate it; if the conventional view is valid, then 4.1 should forecast correctly, and 4.2 should overestimate consumption. The actual errors of the two equations, both with and without autocorrelation correction, are reported in table 5, rows 1 through 4 . Using the permanent-tax concept does not lead to an overestimate of consumption. On the contrary, consumption is somewhat underestimated, though once corrected for the lagged error (row 2) the forecast appears remarkably close, well below one standard error. On the other hand, the equation with the conventional tax treatment, implying a gradual effect of the tax cut, underestimates consumption by greater amounts even after correction for initial error (row 4), though from a statistical point of view the errors-or their difference from those of row 2-are not very significant. This limited evidence is consistent with the hypothesis that permanent tax changes have a prompt effect on consumption.

Notes to table 4.

Sources: See discussion in text.

a. The numbers in parentheses are standard errors.

b. The variables are defined as follows:

$L Y=$ labor income after taxes

$L Y G=$ labor income before taxes

$P Y=$ property income after taxes

$P Y G=$ property income before taxes

$U=$ number of unemployed /number of employed

$S S=$ OASDHI payments adjusted for windfalls

$T R=$ transfer payments other than OASDHI payments

$W_{-1}=$ net worth of consumers at start of quarter

$D=$ dummy variable for surcharge period

$D S S=$ windfall OASDHI payments

$T_{L}=$ labor tax rate

$T_{P}=$ property tax rate

$u_{-1}=$ previous quarter's error.

c. This is the sum of coefficients on the independent variable from period $i-1$ to $i-6$.

d. This is the sum of coefficients on the independent variable from period $i-1$ to $i-8$.

e. The standard errors refer to the estimated equations, which are in ratio form. 
The surcharge in force between 1968:3 and 1970:2 was announced as temporary; hence, our equation 4.4 , which applies directly only to permanent tax changes, should underestimate consumption in this period. In fact, the dummy variable $(D)$ for this period in equation 4.4 is positive and roughly twice its standard error.

Our equation can provide an estimate of the extent to which the surcharge was less effective in constraining consumption than a permanent tax of the same magnitude. This is done by comparing actual consumption first with the value predicted by 4.4 for a permanent tax increase, and second with the value predicted by 4.4 on the assumption that there had been no tax increase at all-which is equivalent to saying that the tax increase had no effect. The estimates are presented in rows 5 through 7 of table 5. Results based on equation 4.3 are similar and are not shown. Row 5 shows the error of forecast during the surcharge period: it is computed without correction for the initial error, which was moderate (some $\$ 2.4$ billion) and could noticeably affect only the initial quarters. Consumption exceeds the computed values in every quarter, confirming the conclusion that treating the surcharge as a permanent tax results in an underestimate of consumption. Row 6 shows the effects on expenditure implied by equation 4.4 for a permanent tax increase with the same rates as the surcharge; it is the difference between consumption estimated by 4.4 with and without the surcharge. Finally, row 7, the sum of rows 5 and 6 , is our estimate of the actual effects of the surcharge on consumption. This estimate is negative everywhere until the final quarter and plausible in shape. It implies that from the second half of 1968 to the end of 1969 , the reduction in consumption was roughly half as large as it would have been had the tax been permanent, which is broadly consistent with Okun's results. ${ }^{19}$ By 1970, however, little of the surcharge apparently was regarded as a permanent tax liability. One might facetiously suggest that by the first half of 1970, after the surcharge was formally given its burial date, consumers knew that it was a temporary tax and treated it as such, but before then they were divided between their hopes and their fears.

\section{THE 1975 TAX REBATE}

Since equation 4.4 yields a credible picture of the response of consumption to the 1964 and 1968 tax changes, what light does it shed on the 1975

19. Okun, "Personal Tax Surcharge and Consumer Demand." 


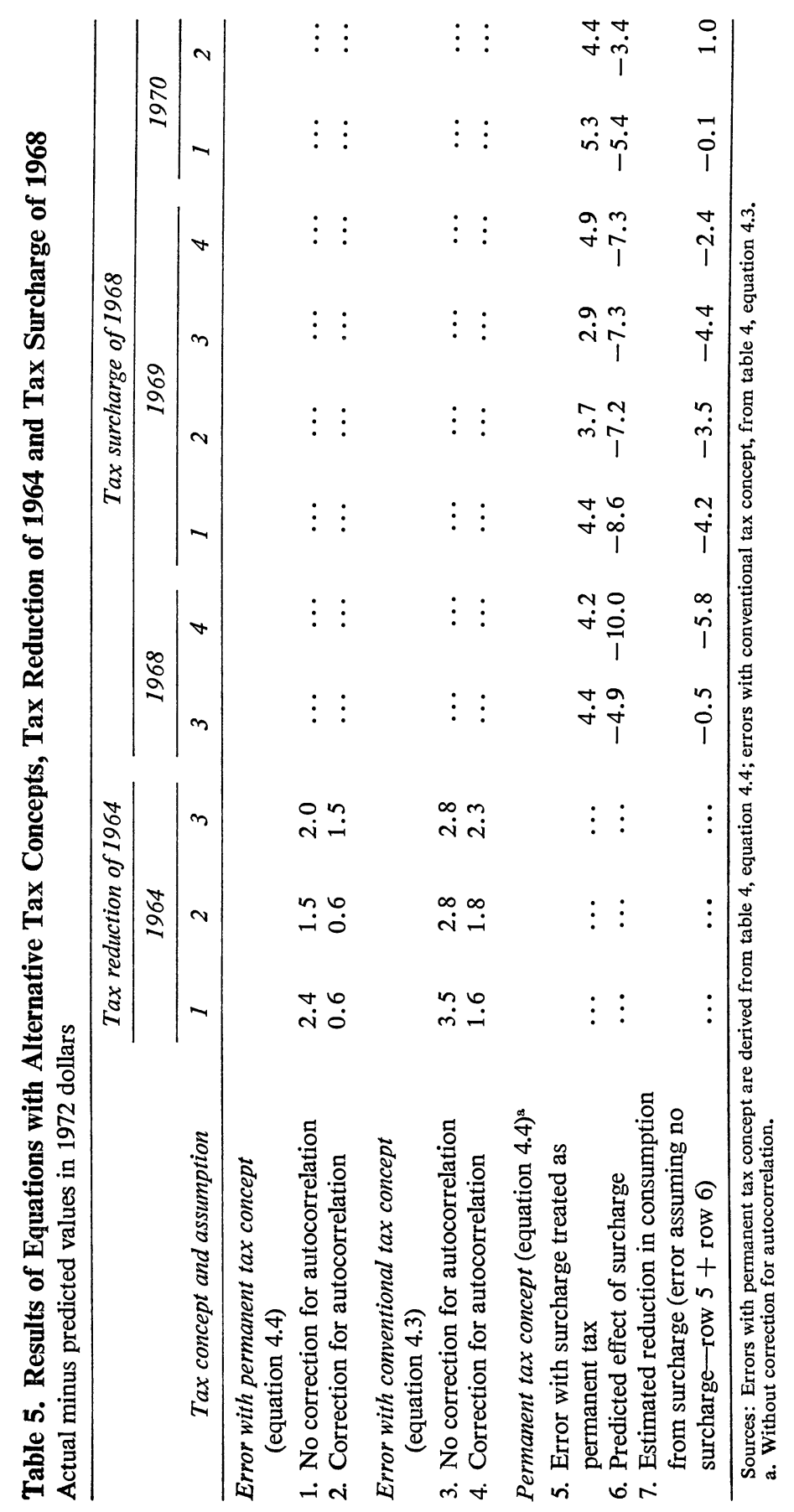


tax rebate? We have extrapolated our equation from 1975:2 through $1976: 3$ on the assumption that there was no tax rebate at all; any excess of actual consumption over this projection will provide an estimate of the response of consumption to the rebate. ${ }^{20}$

Our results are shown in table 6. Row 1 gives the prediction errorsthat is, the estimated actual effect-when the extrapolation is carried out without taking into account the initial error (amounting to some $\$ 3$ billion in 1975:1), while row 2 gives the errors with the autocorrelation correction. All of the entries are positive, implying that the rebate had some effect on consumption, but they are modest, especially for the errorcorrected projections, considering that the rebate was nearly $\$ 26$ billion.

The modest impact of the rebate is illustrated in rows 3 and 4, which cumulate the estimated effects over successive quarters and express them as a percentage of the rebate. The error-corrected projection (row 4) implies that less than one-fourth of the rebate was spent in the first three quarters, while the raw projections raise that estimate but only to onethird. As in the case of the MPS, the estimated effect of the rebate is much stronger beginning with the fourth quarter after the rebate, 1976:1, and both projections imply that nearly all the rebate was spent by the end of the sixth quarter. However, it is hard to take this result seriously because it implies a most improbable pattern of consumers' responses. Our model, like the MPS, may be tending to underestimate consumption in 1976 for reasons such as errors in the independent variables used in the projections that are unrelated to our treatment of the rebate.

The conclusion that no prompt surge of expenditure was caused by the rebate is also supported by the last two rows of the table, analyzing expected and actual changes in saving. ${ }^{21}$ Row 5 gives the actual change in saving, and row 6 the change in saving computed from equation 4.4 on the assumption that consumers totally ignored the rebate. Row 6 only modestly overstates the huge rise in saving in the second quarter, and

20. The information needed to split income, and especially tax liability, between labor and capital after 1974 is not yet fully available and hence we have had to estimate the split relying on extrapolation from earlier data; it seems unlikely to us that errors arising from this allocation would seriously affect the results.

21. For this purpose, "saving" is defined as disposable personal income less consumption, so it includes interest paid by consumers and personal transfer payments to foreigners. These are fairly static series, and thus do not contribute much to the change in saving. 
Table 6. Effect on Consumption Expenditures of the 1975 Tax Rebate, Permanent Tax Model, Quarterly, 1975:1-1976:3

Billions of dollars except as indicated

\begin{tabular}{|c|c|c|c|c|c|c|}
\hline \multirow[b]{3}{*}{ Item } & \multicolumn{6}{|c|}{ Year and quarter } \\
\hline & \multicolumn{3}{|c|}{1975} & \multicolumn{3}{|c|}{1976} \\
\hline & 2 & 3 & 4 & 1 & 2 & 3 \\
\hline \multicolumn{7}{|c|}{$\begin{array}{l}\text { Estimated actual effect of rebate } \\
\text { (error assuming no rebate) }\end{array}$} \\
\hline $\begin{array}{l}\text { 1. Without autocorrelation } \\
\text { correction } \\
\text { 2. With autocorrelation }\end{array}$ & 3.0 & 2.7 & 3.1 & 5.9 & 5.0 & 5.6 \\
\hline correction & 1.4 & 1.8 & 2.7 & 5.7 & 4.8 & 5.5 \\
\hline \multicolumn{7}{|c|}{$\begin{array}{l}\text { Estimated actual effect cumulated, } \\
\text { as percent of rebate }\end{array}$} \\
\hline $\begin{array}{l}\text { 3. Without autocorrelation } \\
\text { correction } \\
\text { 4. With autocorrelation }\end{array}$ & 11.7 & 22.2 & 34.3 & 57.3 & 76.8 & 98.7 \\
\hline correction & 5.5 & 12.5 & 23.0 & 45.3 & 64.1 & 85.6 \\
\hline \multicolumn{7}{|l|}{ Change in saving } \\
\hline $\begin{array}{l}\text { 5. Actual } \\
\text { 6. Predicted }\end{array}$ & $\begin{array}{l}28.9 \\
30.3\end{array}$ & $\begin{array}{l}-20.4 \\
-20.0\end{array}$ & $\begin{array}{l}1.8 \\
2.7\end{array}$ & $\begin{array}{l}-3.9 \\
-0.9\end{array}$ & $\begin{array}{l}3.2 \\
2.3\end{array}$ & $\begin{array}{l}-5.6 \\
-4.9\end{array}$ \\
\hline
\end{tabular}

Source: Derived from table 4, equation 4.4.

generally tracks remarkably well the wide swings in saving during this period.

Again, the modest estimate of the impact suggested by table 6 represents only a point estimate whose reliability must be assessed against the standard error of the equation. This error (roughly one-half of 1 percent of consumption) amounts by 1975 to some $\$ 3.5$ billion to $\$ 4$ billion. Although it is a modest standard error as consumption functions go, it is unfortunately large in comparison with the size of the rebate (approximately 15 percent of the $\$ 26$ billion). Therefore, on the basis of our results, one cannot reasonably reject the hypothesis either that by the end of the first year the proportion spent was negligible, or that it was nearly as large as the rebate. The one hypothesis that we can reasonably reject is that the rebate was treated as two consecutive permanent tax changes; in this case the error would have been $\$ 10$ billion in both 1975:2 and 1975:3. 


\section{Conclusion}

We have tried to provide evidence that consumers respond differently to different types of tax changes, even though these may take away or give them the same amount of cash in the short run, and that the differential response is, at least qualitatively, in line with the predictions of the permanent-income and life-cycle hypotheses. We have been particularly concerned with the effect of a one-time rebate or levy such as the one enacted in 1975 because a similar rebate was proposed in 1977 and may be proposed again despite wide disagreement as to the effectiveness of the 1975 rebate.

In studying the 1975 episode we have relied on three existing models of consumer demand and one especially constructed to study the effect of tax changes. We find an apparent dichotomy between the models of consumption that are fundamentally based upon a single equation (our "permanent tax" equation and the MPS model), and the models that rely on estimating consumption as the sum of many components (DRI and Michigan). The first two models estimate that only a modest fraction of the rebate entered the spending stream in 1975 while the second two estimate that a great deal of the rebate was spent by the end of 1975. Closer examination blurs this dichotomy. The high estimate of spending in the Michigan model comes largely from the furniture equation, which greatly underestimated consumer spending in this area even with the rebate included in disposable income. If we merely cut down the estimated furniture response to that which should have been generated by the rebate according to the model, we get an estimated total effect by the end of 1975 that is close to the one estimated from the single-equation models. No comparable aberrant component stands out sharply in the DRI model, though some of its disaggregated projections raise doubts about its estimates of total consumption. In particular, the estimate of rebate-induced food expenditure is approximately twice that suggested by the model and accounts for a large fraction of the total estimate of rebate-induced expenditure.

We conclude, therefore, that there is strong, though not uniform, evidence that a rebate is not a particularly effective way of producing a prompt and temporary stimulus to consumption.

We would like to emphasize that these results do not imply that the 
alternative to a rebate as a tool of policy is a permanent income tax cut. In the first place, a rebate could be structured so as to be more effective than that of 1975. For example, the now defunct 1977 rebate could have proven somewhat more effective than the 1975 one, since payments were to be concentrated in lower-income groups, including beneficiaries of transfer payments. But, more important, the alternative to a transitory cut in income taxes is not a permanent one, which is simply not comparable since it implies a loss of revenue many times higher. Rather, the alternative is a change in some other tax, and preferably one that is made more, rather than less, effective by its temporary nature. One candidate would be a temporary reduction in sales and excise taxes, which should stimulate consumer spending fairly strongly while it lasted. The bulk of these taxes are paid at the state and local level, but reductions in them could be financed by increases in federal revenue sharing. We do feel that countercyclical tax policy is both possible and desirable, but as the lifecycle and permanent-income theories would predict, we find that the experiences of the last decade do not lend much support to the proposition that temporary changes in income tax liabilities or tax rebates are an efficacious method of rapidly changing consumer spending.

\section{A P P E NDIX}

\section{Alternative Treatment of Other 1975 Tax and Transfer Changes}

As NOTED in the text, the rebate was not the only tax cut in 1975:2. The largest one was the rebate, but there was also an increase in the standard deduction and a $\$ 30$ credit for each dependent. The last two measures, which went into effect on April 30, 1975, were initially labeled as "temporary," but, after many vicissitudes, were reenacted by the end of the year. Our projection incorporates these tax reductions, which means that we implicitly treat them as though they were perceived as permanent from the beginning. It is a relatively straightforward matter to re- 
move this assumption from our estimate of consumer expenditures. Our estimate of the marginal propensity to consume out of "permanent" taxes in 1975 is roughly 0.75 . The value of the nonrebate part of the tax package was approximately $\$ 8$ billion (annual rate) in the second quarter of 1975 and $\$ 12$ billion thereafter (Survey of Current Business, vol. 55, April 1975), or $\$ 6.4$ billion and $\$ 9.6$ billion in 1972 dollars. Since we assume that tax liabilities are averaged over quarters by consumers, this implies a perceived decline in "permanent" tax liabilities of $\$ 3.2$ billion in $1975: 2$, $\$ 8.0$ billion in $1975: 3$, and $\$ 9.6$ billion thereafter. The estimates of consumption can then be reduced by $0.75 x$ (the perceived decline in permanent tax liabilities). A sensible measure of the stimulus afforded by the 1975 package can be given by the estimated increase in consumption afforded by the package (the sum of the residuals in the consumption forecast divided by 4 , to convert annual rates to amount spent) divided by the cumulated loss in revenue by the government; the latter is given by the $\$ 6.4$ billion that the rebate cost the government plus the cumulated loss from the other provisions-which in the first quarter cost the government $\$ 1.6$ billion ( 6.4 divided by 4 ) and in each additional quarter $\$ 2.4$ billion more. If these adjustments are made, we estimate that only about 12 percent of the lost revenue was consumed in the first quarter, and 42 percent by the end of 1975 .

A similar problem results from the $\$ 50$ bonuses paid to recipients of OASDHI and supplemental security income pensions. The bonus cost the government $\$ 6.8$ billion (current dollars at annual rates) in 1975:2. It is listed in the national income accounts and treated by us as a transfer payment other than social security, which has an MPC of 0.94. If it is treated as a social security payment (MPC, 0.67 ) the estimate of consumption in 1975:2 will be reduced by $\$ 1.5$ billion (1972 prices), which will increase the estimated percentage of the rebate consumed by about 5 percent. One may prefer to treat this payment as a windfall. Our estimate of the MPC out of historic social security windfalls is a dubious -0.19 . We hesitate to use this coefficient or, indeed, to treat this payment as a windfall, since social security recipients received a cost-of-living increase in 1975:3, and we feel it is reasonable to assume that this increase was, to a large extent, foreseen by recipients; so the $\$ 50$ bonus (which was roughly equal to the increase that did occur in 1975:3) could be read as an early advance on the raise, not as a windfall. Anyone who feels that this payment was a 
windfall and has an idea of the MPC out of this kind of payment can adjust our estimates. However, we would then suggest that the estimated proportion of the rebate spent-lines 3 and 4 in table 6 -be modified to include the social security payments in the denominator.

\section{Discussion}

Saul H. Hymans: Modigliani and Steindel have carried out an interesting double-barreled attack on the question of whether the temporary tax rebate of 1975 stimulated consumer spending. They investigated the evidence provided by a number of the operating macroeconometric models (DRI, Michigan, and MPS), as well as that provided by their own specialpurpose model (MS) from equations constructed especially to focus on the rebate issue.

The methodology is reasonably straightforward. A given equation is used first to calculate what effect the rebate "should have had" for each quarter in the period 1975:2-1976:3. That same equation is then run over the same period using actual predictor variables (but generating its own lagged consumption data or lagged residuals when appropriate) and its residuals are calculated. If an equation implies that the rebate should have increased consumption by $\$ 5$ billion in 1975:2 and then the equation overpredicts actual consumption by $\$ 4$ billion in 1975:2, it is estimated that the rebate resulted in only $\$ 1$ billion of additional consumption.

When the authors apply their methodology, they obtain rather varied results from the different models and equations. Thus the MPS model indicates that 30 percent of the 1975 rebate was spent in the first two quarters (1975:2 and 1975:3); DRI comes out with 58 percent spent in two quarters; Michigan 50 percent; and the special-purpose MS equation yields an effect of only $12 \frac{1}{2}$ percent in two quarters. If Michigan and DRI are close to the mark, then the tax rebate of 1975 would have to be judged as having been an effective "quick fix" for consumer demand; if MPS and MS are the more reliable, then the tax rebate cost the federal treasury a lot of bucks for very little bang. Extending the analysis to four 
quarters (1975:2-1976:1), the authors find the following estimates of the amount of rebate spent: MPS, 61 percent; MS, 45 percent; Michigan, 130 percent-again a substantial difference, with MPS and MS indicating a rather disappointing impact after one year and Michigan a huge impact. Modigliani and Steindel then proceed to reject results such as those shown by DRI and Michigan and accept the more modest impacts inferred from MPS and MS. DRI's estimated effects put more of the additional consumer expenditure in food and housing services than the authors can find believable. Michigan's estimates of 50 percent and 130 percent after two and four quarters, respectively, would have been reduced to 18 percent and 37 percent if the effects estimated to be due to furniture (and household equipment) were eliminated. Since the furniture (and household equipment) effects are so "implausible," Modigliani and Steindel conclude that the corresponding equation in the Michigan model must be "quite unstable." This conclusion brings Michigan into line with the results shown by MPS and MS, adding further support to a negative conclusion regarding a quick and sizable impact from a tax rebate.

The extent to which the results of MPS, MS, and "Michigan excluding furniture" may be considered comparably reliable is shown in the following comparison of residuals (in billions of 1972 dollars) for the 1975:21976:3 period:

$\begin{array}{cccc} & M P S & M S & \begin{array}{c}\text { Michigan } \\ \text { excluding furniture }\end{array} \\ 1975: 2 & -5.0 & 1.4 & -5.3 \\ 3 & -0.3 & 1.8 & -2.1 \\ 4 & -1.7 & 2.7 & -2.7 \\ 1976: 1 & 4.6 & 5.7 & 3.9 \\ 2 & 2.1 & 4.8 & -0.2 \\ 3 & 1.7 & 5.5 & 0.5 \\ \text { Root mean-square } & & & 3.07 \\ \quad \text { error } & 3.07 & 4.05 & -1.02 \\ \text { Bias } & 0.23 & 3.65 & \end{array}$

On the whole, MPS and Michigan excluding furniture-with no special treatment distinguishing between temporary and permanent taxes-do somewhat better on RMSE grounds than MS, which assumes that temporary tax changes have no effect on consumer spending; but the differences are relatively small. In a rough way, it appears that MS exhibits a progressively worsening underprediction by ignoring the 1975 tax rebate entirely, while MPS and Michigan excluding furniture overpredict con- 
sumption in the quarters immediately after the rebate and then begin to underpredict after three quarters. From the bias, however, it appears that MS would have to be interpreted as providing a lower-limit estimate of the rebate effect over a six-quarter span, whereas MPS and Michigan excluding furniture "work out their errors" and come out about right after six quarters.

Now what of the furniture (and household equipment) error in the Michigan model? The Modigliani-Steindel suggestion that the equation must be out of control or "unstable" hardly seems warranted. As estimated (through 1974:4) the equation has a standard error of $\$ 0.43$ billion (1972 dollars) and its single-equation residuals around the time of the 1975 rebate are as follows:

$\begin{array}{rr}1975: 1 & 0.18 \\ 2 & 2.05 \\ 3 & 2.28 \\ 4 & 2.30 \\ 1976: 1 & 0.75 \\ 2 & 0.96 \\ 3 & 1.17 \\ 4 & 0.30\end{array}$

Thus the equation was on track in 1975:1, way off during 1975:2-1975:4, and back to track by the end of 1976 . Should the huge and very systematic underpredictions of $\$ 2$ billion to $\$ 2.3$ billion in 1975:2-1975:4 be regarded as evidence of an incredibly unstable equation, or did furniture and household equipment really benefit from the tax rebate? In truth, it's difficult to believe that furniture and household equipment benefited to the extent estimated by the Michigan model, but something certainly happened to an equation that has not generally been very troublesome within the model, and that now appears to be on track again. The rebates of 1975 were of the order of $\$ 100$ per household_an amount that buys outright a small item of furniture or a minor household appliance, or that makes a significant downpayment on a major household durable. With the auto market still reeling from the oil embargo at the time of the rebate, is it so unreasonable to believe that household furniture and appliances were a major beneficiary of the tax rebate? The permanent-income lifecycle analysis certainly would have to regard the purchase of such durables as a logical way to "save" and provide a future flow of consumption services. 
The issue of the effectiveness of the 1975 tax rebate hardly seems to have been settled by the Modigliani-Steindel study. Further analysis seems to be in order, and I suggest that the pessimistic conclusion of Modigliani and Steindel should be regarded as highly tentative.

F. Thomas Juster: I have two comments on the Modigliani-Steindel paper on the effect of tax cuts on consumption and consumer spending. The first relates to their reference to some results contained in a paper of mine on the same subject ("A Note on Prospective 1977 Tax Cuts and Consumer Spending"). The second relates to their procedure for estimating the effect of rebates. Finally, I would also like to comment on the effect on consumers and consumer spending of the administration's decision to drop the tax rebate.

Modigliani and Steindel view my results as evidence that neither transitory nor permanent tax cuts would have much impact on consumer spending during 1977 because the adjustment processes are relatively slow. While this assessment is technically correct with respect to the point estimates in my equation, I would not make the same inference as they do, for two reasons.

First, in the process of examining the impact of tax changes on consumption in the model, I experimented with the idea that the effect of tax changes is different for tax increases and decreases. Although the evidence in favor of a differential is not robust ( $t$ ratios are around 1 ), the point estimates indicate that a tax cut has more impact on consumption than a tax increase; that is, a tax reduction affects consumption more than the overall coefficient suggests, while a tax increase affects consumption less. Given the stickiness of consumption in the face of income declines emanating from any source and the presumption that windfalls of all sorts (including rebates) represent opportunities for consumers to eat into their list of unmet consumption needs, I find those results plausible. They imply that the response to a tax cut might be substantially faster than indicated by the Modigliani-Steindel analysis.

Second, the response pattern in my equation is, of course, based on point estimates of the tax and lagged-saving coefficients. In the paper, I suggest that the coefficient of lagged saving is likely to be biased upward because conventionally measured saving (which is the dependent variable) has serially correlated errors. To test the sensitivity of the equation to that presumption, I experimented with constraints on the lagged-saving 
coefficient. The point estimate was 0.91 , and the constraints ranged down to 0.7 . It turned out that the constrained equation also makes the taxchange coefficient smaller in absolute terms, implying that the entire process of getting tax rebates or other tax cuts into the spending stream might be substantially more rapid than the point estimates indicate. The other variables in the equation are hardly affected by the constraint, and the standard error of estimate rises by less than 10 percent even with the 0.7 constraint (which is about four standard errors away from the point estimate). I infer that there is a band of plausible outcomes described by the constrained regressions and that the Modigliani-Steindel estimate of response from my equation is at one end of the plausible range.

The next issue concerns the specification of the basic equations in the Modigliani-Steindel paper. The authors estimate consumption patterns without rebates (or, in the case of 1968, without the temporary surtax) by using prediction errors from a simulation that ignores the existence of temporary tax changes. But that procedure holds up only if the equation is perfectly specified; otherwise errors arise from a combination of causes, only one of which is the omitted transitory tax change. Interestingly enough, their preferred equation has a time path for the rebate part of the 1975 tax cut that is not credible, as they themselves point out: it implies that the effect of the rebate accelerates through time, being larger in the fourth through the sixth quarters after the rebate than in the first through the third quarters.

One possibility is that the Modigliani-Steindel equation systematically underestimates the upward trend in consumer demand during 1975 and 1976 because it contains no way to model the reduced uncertainties faced by consumers during this period of recovery. If that is so, their severe underprediction for 1976 would be explained (because uncertainty was low then), and it might well be true that their predicted values for consumption during 1975 would be lower than shown (because uncertainty was high then). Thus the overall result could easily be a rebate pattern that is substantially larger in the early quarters, substantially smaller or negligible in the later quarters. That kind of time pattern certainly makes more sense, and it could totally reverse their conclusion that only about one-fourth to one-third of the rebate was spent during the first three quarters.

In sum, if the Modigliani-Steindel equation is misspecified because it excludes any measure of consumer response to changing uncertainty over 
the 1975-76 period, I do not see how one can tell anything from that equation about the effect of the rebate, since the observed errors are a combination of a missing uncertainty effect and an omitted rebate effect. Modigliani and Steindel want to use errors in their equation to measure the second, but the errors may be measuring a combination of the two as well as other unspecified influences on consumer spending.

Finally, I have a brief comment about the possible effects of the recently announced decision to drop the rebate from the administration's plans for 1977. In a Survey Research Center study conducted in February 1977, we inquired about the effect of the rebate. About 60 percent of consumers expected the rebate to become law, about 70 percent thought that it would be good for the economy, and about 80 percent were in favor of it. Thus a considerable majority of consumers expected the rebate to pass and thought it would be good for the economy.

Analysis of the effect of the rebate on consumer optimism shows an interesting result. Dividing the sample into those expecting the rebate to pass and those expecting something else (not to pass, uncertain, and so on), there is little or no difference between the two groups in perceptions of past income change or business conditions, but there is a big difference in expectations about the future. Respondents expecting the rebate to pass were much more optimistic about business conditions, both over the next year and over the next five years, and about whether market conditions for buying houses and household durables would be favorable or unfavorable. Overall, the index of consumer sentiment stood at 90 for those expecting the rebate to pass and at 80 for others.

Thus the relatively high level of optimism shown in the February 1977 survey of consumer attitudes must be attributed in part to the widespread presumption that the rebate would pass and that it would have favorable effects on the economy. The decision to forgo the rebate will therefore produce disappointment and some negative effect on the general level of consumer optimism, in addition to its direct effect on consumer income and expenditure.

\section{General Discussion}

Arthur Okun applauded the way the authors had separated the response to tax changes from the response to changes in pretax incomes, 
noting that this practice accorded with the spirit of the life-cycle formulation. He thought that the procedure could usefully be pushed further to distinguish between overtime and straight-time pay, year-end dividends, and so forth. But, he emphasized, the results pointed to a rapid consumption response for most types of income. He also found it amusing that the authors were willing to attribute full effectiveness to the nonrebate portion of the temporary 1975 tax cut, which was, in his view, closely analogous to the 1968 surcharge.

Both Okun and Lawrence Klein questioned the analysis of the disaggregated components of the models. Okun said that disaggregated equations are used to take advantage of the ability to identify factors that influence demand in particular sectors, and that, in summing to totals, one expects some canceling out of errors with opposite signs. He objected to the concept of "estimated actual effect" in tables 2 and 3. It was clear, for example, that DRI underestimated food outlays in 1975:2 and 1975:3 on any view of the effectiveness of the rebate; but the error was largest assuming no effect of the rebate. Klein felt that the amounts attributed to the rebate fell within the standard tolerance intervals of predictions from the sectoral equations. He also pointed out that most observers expected the rebate would be spent on nondurables such as food and clothing and other "small ticket" items. Since the model equations could not have been estimated to take explicit account of an event such as the rebate, one would expect spending in these areas to be exceptionally strong when the rebate was treated simply as a normal increment to income. 